\title{
Research on the Chinese Ten-Stringed Guqin of Marquis Yi: Design Ideas and Origin of Its Shape
}

\author{
Kenan Yao \\ Huazhong Agricultural University, Wuhan, China \\ Email: ykn@mail.hzau.edu.cn
}

How to cite this paper: Yao, K. N. (2019). Research on the Chinese Ten-Stringed Guqin of Marquis Yi: Design Ideas and Origin of Its Shape. Art and Design Review, 7, 10-21.

https://doi.org/10.4236/adr.2019.71002

Received: August 20, 2018

Accepted: December 24, 2018

Published: December 27, 2018

Copyright $\odot 2019$ by author and Scientific Research Publishing Inc. This work is licensed under the Creative Commons Attribution International License (CC BY 4.0).

http://creativecommons.org/licenses/by/4.0/

\section{(c) (i) Open Access}

\begin{abstract}
As the earliest Guqin unearthed in China by now, the ten-stringed Guqin of Marquis Yi offers a view of the early appearance of its kind. Its shape and embellishments embody the belief, totem worship, ruling ideology, moral criteria and universe philosophy of the Chu people during the Warring States Period, as well as their attitudes towards this ritual vessel, which dates back to the time immemorial, and its cultural identity. Through induction and analysis of documents and interviews with the restorer of the unearthed Guqin, this paper probes into the origin and design ideas of the shape and the strings of this ten-stringed Guqin so as to uncover its cultural connotation and functional reference.
\end{abstract}

\section{Keywords}

Ten-Stringed Guqin, Origin of Shape and Construction, Worship for Shamanism and Loong (or Chinese Dragon, a Miraculous Animal in Chinese Legends), Yin-Yang and Five Elements Theory

\section{Introduction}

Guqin (or Qin) is a history-honored typical ritual vessel in China. By now the earliest surviving Guqin in China is the ten-stringed Guqin unearthed in the tomb of Marquis Yi (ruler of Zeng State in the Warring States Period) in 1978 (Hubei Museum, 2001). It is believed by most experts that the appearance of the early Guqin exemplifies people's views and attitudes towards the ritual vessel and its cultural identity during the Warring States Period. Thus, research on the design ideas of the ten-stringed Guqin and the origin of its shape can shed light on its cultural connotations and offer reference to its historical development and 
future trend.

The unearthed Guqin is 67 centimeters in length and 19 centimeters in width, with its head and tail slightly warping up and the waist narrower and concave (Figure 1). The top board of the Guqin is made of one piece of wood, and the bottom board is movable. The half-box structured sound box is connected to the long tail, with a Yanzu ("goose foot", or "dragon foot", which supports the Guqin) below. There is no Hui (studs, marking the phonemic level) on the playing area, but some decorative lines. On the Yueshan ("bridge"), there are 10 string holes, 1.6 centimeters away from each other, with obvious traces, proving it had once been used (Tan, 2001a). In the Longchi (means "dragon pond") at the bottom there are 4 tuning pegs. Covered with black lacquer, the Guqin was still lustrous when unearthed, though having stayed in water for several thousand years. The unearthed ten-stringed Guqin indicates the previous assumption "the Qin made by Shennong originally had five strings and two emperors of Zhou Dynasty added the sixth and seventh strings to it respectively" wrong. Moreover, this ten-stringed Guqin is very different in shape and size from the seven-string Guqin, which has survived the long history.

\section{The Status and Role of Guqin during the Warring States Period}

Marquis Yi, the king of the State of Zeng, shared the same surname Ji with the royal family of Zhou Dynasty and the same cultural root with the states in Central China (Zhao, 1992). However, owing to the declining of the royal family and itself, Zeng had become a vassal state of the state of Chu by the time of Spring and Autumn Period, with its culture affected significantly by the Chu culture, too (Tan, 2001b). But whether in the Central Plains where the royal family lived or in Chu State, which used to be called Nanman (barbarous area), Guqin enjoyed a high status in the ritual system. In the book Analytical Dictionary of Characters, it is explained that Qin, invented by Shennong (god of farming in legends), has a similar pronunciation to jin, which means prevention ( $\mathrm{Xu}, \mathrm{Han}$ Dynasty, a). In the article An Discussion on Qin, Liu Ji from the Southern Song Dynasty further explained, "Qin means jin, namely, prevention. It forbids the evil and guides the mind to the righteous. It was initially played by Fuxi (one of the most ancient gods in Chinese legends) and developed by the two kings of

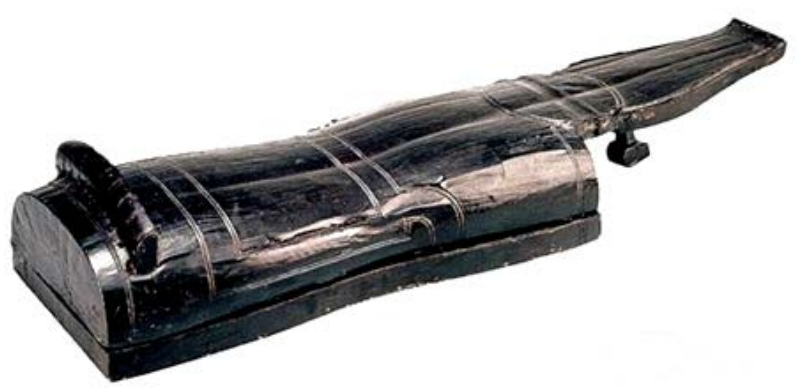

Figure 1. Top: The Chinese Ten-stringed Guqin of Marquis Yi. 
Zhou Dynasty. Its image represents the heaven and earth; its quality reflects Yin and Yang... it offers people pleasure, but not debauch. It helps to put the society into harmony. People who are good at appreciating the Qin can predict the fortune of themselves and even that of the country; people who are good at playing the Qin have the capacity of converting Yin and Yang, and even summon the spirits. Thus, the ancient chinese people would always have books and Qin by their side and never remove them with no reason. Qin is of such great significance as a symbol of righteousness."

It was believed by many philosophers and rulers of ancient China-such as King Wu of Zhou, Confucius, ShiKuang-that music could cultivate tastes and convey emotions. Knowing music was thus considered to be a noble character in public life that all well-mannered men with decency and insights were supposed to master it. In the Western Zhou dynasty, Guqin gradually became a ritual vessel in the trend of "cultivating virtue by music". In Rites of Zhou it is recorded that "Gumeng (a kind of official historian), is in charge of playing all kinds of instruments including Tao, Zhu, Yu, Xun, Flute, Pipes and Strings, singing suggestive poems and historical songs. He would conduct big bands to perform songs like Nine Virtues and Six Poems. " (Lv, 2004). This implies that Guqin and Guse (another musical instrument) played an important role in exposing current social problems and providing advice to the rulers). Through these ceremonies, Qin gradually became a ritual vessel to educate people and establish morality. That was the reason why it had kept rising in status and finally became a vessel used by the ruling elites (Zhong, 2013a). By the time of the Spring and Autumn Period and the Warring States Period, Qin had already become an essential ritual vessel of ancestor worship. It is also recorded in Rites of Zhou that "on the Winter Solstice, people should play the Guqin and Guse made of woods from the Yunhe Mountain, performing the Yunmen dance ${ }^{1}$ on the sacred mound... on the Summer Solstice, people should play the Guqin and Guse made of woods from the Kongsang Mountain, performing the Xianchi dance on the small island in the water... people should play the Guqin and Guse made of woods from the Longmen Mountain, singing the Nine Virtues song and performing the Jiushao dance in the ancestral shrine." (Lv, 2004). We should notice that the "sacred mound" and "ancestral shrine" mentioned are both places for revering heaven and imitating their ancestors. The description implies the paramount status of Guqin among ritual vessels.

\section{Design Ideas of the Shape}

This ten-stringed Guqin was not made out of craftsman's private interest, but an integration of the profound cultural traditions, philosophy and ruling ideology of its time. Through the research on ancient documents, the author of this paper conceived that the shape of the ten-stringed Guqin as Loong (or Chinese dragon, a miraculous animal in Chinese legends) has embodied the wish of its owner, namely, consolidating his status, revering divinities and ancestors and most im-

${ }^{1}$ Yunmen Dance is the Chinese most ancient and mysterious of dances. 
portantly, leading his soul to heaven. Evidences can be found in the following two aspects.

\subsection{Cultural Background: Chu People's Worship for Shamanism and Loong}

In order to explore the origin of the Guqin's shape, we need to start with the culture of the Chu State. Since the Western Zhou dynasty, states in Central China had shared the tradition of Loong worshiping, which can be proved by the substantial relics unearthed in later ages. They idolized Loong as their totem and used ritual vessels with the images of Loong in sacrificial ceremonies to pay their tribute to their ancestors.

Records on the Chujian (bamboo slips) ${ }^{2}$ unearthed in Jingmen prove that the Chu people regarded Laotong, Zhurong and Yuxiong as their ancestors. The clan of Zhurong from the Central China made up the royal clan of the Chu people (composed of the royal clan and the common one) and brought many customs, etiquette and totems to State Chu. And the culture of Zeng State, which was very close to that of Chu in the north, was also influenced by the Central Chinese culture (Huang Ying, 2015). The ruler's promotion of the Loong worship was actually the embodiment of the combination of the Central Chinese culture and tribe culture of the north, which was rather diverse.

Another reason of the Loong worshiping was that the Chu people viewed Loong as the symbol of royal omnipotence. According to the Instruction (a book explaining other books like Historical Records) written by Pei Yin, it was believed that "Loong outclasses men; so does the emperor". And in Book of Documents, it wrote that "emperor, is also known as Loong". We can find the origin of these ideas in Chu culture (Zhang, 1992a). As recorded in Huainanzi (a collection of papers of Taoism), long before the Spring and Autumn Period, Chu people would have a big bell with the image of nine Loongs placed in the royal palace. And in the $9^{\text {th }}$ year during the king Helv's reign (506 A.D), there was a war between State $\mathrm{Wu}$ and State Yue (Chen, trans, 2012). In the battle of Baijv (a significant battle known for its large scale and profound influence in history), the army of $\mathrm{Wu}$, under the command of the famous militarist Sun $\mathrm{Wu}$ (also known as Sunzi, wrote the book Art of War), broke into yingdu, the capital of State Chu. After that they burned the grains in the city and destroyed the bell for burning the grains would jeopardize the economy of $\mathrm{Chu}$, and destroying the bell symbolizes breaking its royal omnipotence (Zhang, 1987a).

Besides, the Loong worship also indicates the spiritual pursuit of the Chu people. An important characteristic of ancient Chinese civilization is its division of the world into different parts, including that of heaven, of earth, of human and of gods (Zhang, 1986). Chu people divided the world into three strata,

${ }^{2}$ The bamboo slips are unearthed in Baoshan, Jingmen city. The slip No. 217 wrote “...sacrifice one female sheep respectively to the ancestors of Chu, Laotong, Zhurong and Yuxiong” and the No. 237 wrote "...sacrifice two female sheep respectively to the ancestors of Chu, Laotong, Zhurong and Yuxiong”. 
which was also called three realms, and believed that the soul was eternal. That explains why they paid special tribute to spirits. In Book of Han it was recorded that $\mathrm{Chu}$ people believed in the existence of ghosts and attached great importance to sacrifice ceremony (Yan, Trans., 1990). Zhang Zhengming, an expert in Chu culture, also mentioned in his book that Chu people's worship for spirits was incomparable among all the nations in China (Zhang, 1987b). In the famous piece Nine Songs in the The Songs of Chu (written by the famous poet Qu Yuan), there are eleven songs. Except one, the other ten are all about sacrificial ceremony and ritual manner of the royal families. Therefore we can infer that the reverence for gods and spirits was very popular among people then, and in fact, it remains to influence today's culture. On the other hand, from an anthropological and sociological perspective, shamanism is also a pattern of the early human civilization. In the remote past, the shamans would play the role of doctor, intellectual, artist, prophet, religious leader and psychic. J.G. Frazer, an anthropologist deems that shamanism is the origin of religion and art, and witchcraft is actually a fake craft through which men imagine they have conquered nature. Thus a correct understanding of shamanism will help us understand the special shape of the ten-stringed Guqin.

Since the Chu people believed in immortality, they wished their soul would reach heaven after death. Then Loong became an essential carrier to lead the soul to the future life. So we can find a great amount of descriptions about "riding Loong" in the literary works of Chu. Chu people described the image of Loong in a mysterious and idealized way. One of their purposes was to lead their soul to the heaven, so Loong was considered as a fantastic carrier. Because of the symbolic meaning of Loong in legends and the idealization of its image, it gradually evolved into a symbol of divinity as well as appreciation of beauty and worship in Chu people's life. Accordingly, it is an inevitable result of history that its image is used in the embellishment of ritual vessels.

\subsection{Shape of the Ten-Stringed Guqin as a Kui Loong}

The unique shape of the ten-stringed Guqin reminds us of Kui Loong, a legendary animal. In Analytical Dictionary of Characters, Kui Loong is described as "a divine animal like Loong, with one sole foot, horns, hands and a face like that of man" (Xu, Han Dynasty, b). In The Classic of Mountains and Rivers, the description for this animal is slightly different: "an ox-like animal with dark black body, no horns and one sole foot; its movements would cause rain and wind; it gives out light like sunshine and moonlight and sounds like the loud thunder" (Yuan, Trans., 1992). These two descriptions share something in common about Kui Loong: animal-like appearance and one sole foot. Apart from the direct descriptions, we also find some relevant information. As recorded, in the ancient time, the music official was also named Kui (the same name of this legendary animal) to show its authority. Confucius talked about him in a conversation with the emperor of Chu: "in the remote past, Shun (a legendary monarch in ancient 
China), intended to put the world in order, so he appointed Kui, a music talent coming from nowhere, as the one in charge of music; thus Kui examined the tones of music and achieved balance in Qi of Yin and Yang, so that the people became obedient" (Chen, Trans., 2002). It is reasonable to conceive that Kui Loong also have the power to modify music, which is the third characteristic of this legendary animal.

Though Kui Loong is a fictitious animal that only exists in legends, we can find many evidences to explore the origin of its image. He Xin, a scholar talked about the prototype of Loong in his book Loong and Phonix. the prototype of Loong was the ancient estuarine alligator in the lizard family and it had been proved by literature and archaeological findings... The Kui, in fact, was alligator ... and alligator was Loong (He, 2007). Another scholar Wang Dayou, believed that the prototype of Loong was the Yangtze alligator and it was a mixture whose principal part is made up by alligator, snake and fish, and other parts compounded by birds and animals, which become the totems of tribes. The earlier images of Loong in painting resemble alligator more (Wang, 2008). According to Wang, in spite of the great changes of Loong's image later, the main body of it does remain to be that of an alligator. From this we can infer that the image of Kui Loong in State Chu may also originate from the Yangtze alligator if Loong does (Figure 2).

Through the observation of the ten-stringed Guqin, it is not hard to find that the shape of this Guqin does resemble Kui Loong. Firstly, it has the features of a alligator: plump body, slim waist, four short legs (not foot) and one elongated tail. Secondly, it also has the features of a Kui Loong: shape of an animal, black body and one foot under the tail. Zhong Chunhui, a Qin expert, discussed about this ten-stringed Guqin in his book View of Ancient Qin. He mentioned that Qin, as a musical instrument, had close connection to Loong (Zhong, 2013b). The

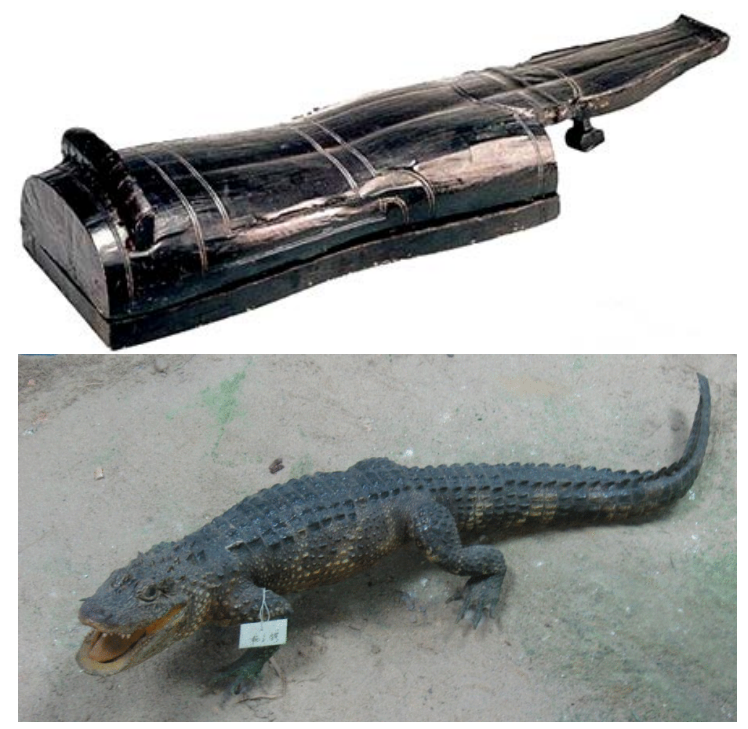

Figure 2. Top: The shapes of Chinese Ten-stringed Guqin of Marquis Yi and Chinese alligator. 
ten-stringed Guqin unearthed in the tomb of Marquis Yi, had tail similar to that of fish with one foot under it. Seeing this, we could not help thinking of the Kui Loong in the ancient legends. Wu Zhao, a Guqin expert and musician, also notices the similarity between Guqin and Kui Loong. Thirdly, since the ancient people believed that Kui was in charge of music, and Guqin had noble status as a musical instrument in the ritual vessels (Yang, Trans., 1981), in the author's view, it is reasonable for people in Zhou dynasty, where ritual vessels were endowed with symbolic meaning, to shape the Guqin into a Kui Loong to represent the royal status. Fourthly, as mentioned above, in the sacrificial ceremonials for their ancestors, Chu people would use Guqin to pay their respect for their ancestors (Zhang, 1992b). And Loong, had always been the totem of Chu and was even considered an intermediary form of life after human's death. Thus Guqin shaped into a Loong was considered to guide the soul to the heaven. Fifthly, Loong also symbolizes royal omnipotence in $\mathrm{Chu}$ while music represents the feudal code of ethics. Making the Qin into a Kui Loong, the combination of power and ethics, can carry people's spiritual pursuit.

\section{Design Ideas of the Strings}

Besides its shape, the strings of the Guqin also give expression to ancient philosophy. As is known, Qin in later ages has only seven strings. However, this Guqin found in the tomb of Marquis Yi has ten. The author of this paper believes that the reason lies in its close connection with Yin-Yang and Five Elements theory, the performing manner and the ruling ideology.

\subsection{Relations between Melody and Yin-Yang and Five Elements Theory}

Chinese people had put forward the theory of Tao long before the Spring and Autumn Period. It was believed that "the dialectic relation between Yin and Yang, such as nothing and ens, earth and heaven, female and male, is just the basic principle of Tao" (Lao, Spring and Autumn Period). Laozi also talked in Tao Te Ching. The Tao produced One; the One produced Two; Two produced Three; Three produced All Things. All Things leave behind them the Obscurity (out of which they have come) and go forward to embrace the Brightness (into which they have emerged), while they are harmonized by the Breath of Vacancy. Articles in Huainanzi further explains the theory of Yin-Yang: Tao means discipline, initiated from One; while One cannot give birth to everything in the world, thus it divides into Yin and Yang; Yin and Yang combined produce everything (Xu, Trans., 1995). All these show that people back then believed in dualism, where everything in nature was divided into two sides, Yin and Yang, contradictive but also convertible to each other.

Later the theory of Five Elements came into being and gradually became an important cognitive system people adopted to understand the world, which found its way to the widespread universe philosophies of the one hundred 
schools of thoughts and various fields such as literature, witchcraft, medicine and divination. It was regarded as an advanced theoretical system to guide people's culture, spirit and other activities. By the end of the Spring and Autumn Period, the theory of Yin-Yang and Five Elements had become quite complete, it had become a law of thoughts and belief in the system of the universe as well (Gu Jigang, 1930). Every one of the Five Elements could be divided into two aspects, Yin and Yang. As Zhuangzi (a book written by the representative figure of Taoism, Zhuangzi, famous for his humor) wrote, when wood rubs wood, there comes fire; when gold meets fire, it turns into liquid (Chen, Trans., 1983). If Yin and Yang is converted with each other, the world would be shocked. For instance, thunder is the consequence of fire in water, which would ruin the trees. This proved that in the Zhuangzi's philosophy, Yin and Yang exists in the Five Elements. And we can also find the combination of Yin-Yang and Five Elements in the Heavenly Stems and Earthly Branches in traditional Chinese lunar calendar.

Zhu Changwen, a theorist in Northern Song dynasty mentioned in his book History of Qin that the saints formulated the basic five tones, Gong, Shang, Jue, Zhi and $\mathrm{Yu}$ (do, re, mi, sol, la, respectively), from the observation of Five Elements in the natural phenomena. Gong represents earth, standing for royalty, honesty and consideration; Shang represents gold, standing for officials, righteousness and speech; Jue represents wood, standing for citizens, humanity and appearance; Zhi represents fire, standing for work, courtesy and inspection; Yu represents water, standing for matter, wisdom and listening (Zhu, Northern Song dynasty). Thus in his opinion the five tones were made according to the Five Elements in light of the Yin-Yang and Five Elements theory, imitating the moves of the heaven and earth. The famous musician Ji Kang (A.D 223-263) also indicated that the heaven and earth gave birth to everything in the world; summer and winter took turns to come, so the Five Elements came into being; the appearances of them were the five colors and the sounds of them were the five tones (Han, Trans., 1997). This explains ancient people's view on how music is created. It was believed that music, with the power of reaching the divine, was the most harmonious way for humanities to communicate with the nature. And people made the musical instruments like Guqin according to the same principles they made the five tones. The tones are embedded with the qualities of the Five Elements, as parts of the universal system in the same time and space, just like the other natural existences in the world. They corresponded with the Five Elements (gold, wood, water, fire and earth), with the twelve months of a lunar year, and with the four seasons and five directions. Therefore, the musical system based on the five tones is also considered as a recycling system with Yin and Yang and Five Elements (Chen, Trans, 1983).

\subsection{Size and Playing of Guqin}

Tan Heng wrote in New Talks, "after Shennong succeeded Fuxi to become the 
new ruler of the world ... he made a Qin, with wood cut from the parasol tree as the body and silk as strings, so as to communicate with gods and bring the heaven and earth into harmony. The Qin is $3.66 \mathrm{chi}(1 \mathrm{chi}=33.33 \mathrm{~cm})$ long, symbolizing the 366 days of a year; it is 1.8 cun $(1 \mathrm{cun}=3.33 \mathrm{~cm})$ thick, representing 3 multiplied by 6; it is 6 fen ( $1 \mathrm{fen}=0.33 \mathrm{~cm}$ ) wide, standing for six tones." (Tan, Han Dynasty). Cai Yong also mentioned in Guide to Qin Music, "Qin is 3.66 chi long, which reflects the 366 days in a year; it is 6 fen wide, which symbolizes Liuhe (up, down, east, west, north and south, referring to the world or the universe)." (Cai, Han Dynasty). That is to say, the length of Guqin in Han dynasty is about $120-125 \mathrm{~cm}$, and the width is generally $20 \mathrm{~cm}$, which is much larger than the ten-stringed Guqin we found. By now, the size of Guqin is basically the same as that of the Han dynasty. We can refer to the records in Book of Documents, which indicates the then playing manner of Guqin is to stroke gently the Qin with certain devices and perform it in accordance with the beat $(\mathrm{Mu}$, Trans., 2009).

In Book of Songs, we can find many records: "I have fine guests; so I strum these and strum the Qin..."; "sound relationship between husband and wife is like the harmonious melody of Qin and Se drummed together; so is the good relations between siblings"; "people beat the Qin, Se and drum to welcome the god of farming; they pray for timely rain for a bumper harvest, so that men and women can be free from hunger". From these we can see that when playing Qin and Se, people use the method of gu (drumming). The numerous records in classical Chinese literary works such as in Book of Zhuangzi (Zhuangzi, one of the most important representative figures of Taoism), The Spring and Autumn Annals, Book of Liezi (Liezi, another representative figure of Taoism), Book of Mencius and Historical Records also support this opinion.

Thus we can confirm that the conventional performing manner is gu (drumming, or hitting). In Analytical Dictionary of Characters, we can find the explanation of gu, that is, "the voice of spring, when the living things break through the restraints and turn up in the world" (Xu, Han Dynasty, c). The right part of the character gu means "to hit with hand". This is very different from the later method, which covers various techniques. The basic ones include the eight actions: supporting, striking, rubbing, picking, drawing, scraping, hitting and plucking, all requiring flexible maneuvers of four fingers. Therefore, the distance between strings cannot be too narrow, otherwise the fingers fail to move accurately. Even if the player can barely play out sound, he may easily touch the string and cannot play fluently (Zhang, 2014). Thus, the playing method of ten-stringed Guqin of Marquis Yi is drumming, which explains why its size is much smaller than that made after Han dynasty. On such a narrow surface, with over 10 strings and the close distance between them, it is unlikely to play this

${ }^{3}$ Zhuangzi: "one day when out in the forests in Ziwei, Confucius takes a rest in a temple; he hits the Qin and sings songs when his disciples read."

${ }^{4}$ Liezi: "one day Confucius is traveling in the Mount Tai, when he is met by Rong Qiqi, an old man, who drums the Qin and enjoys himself very much.” 
Guqin the way we did after Han dynasty.

From above we can conclude that the playing manner of the ten-stringed Guqin, with such a narrow surface and distance between the strings, is drumming, which, unlike plucking, could not make out too many tones, which explains why there are as many as ten strings. Through the many strings, more tones can be created. That is how the varied melodies are created. According to the guideline theory of music, the Yin-Yang and Five Elements theory, the change of tones requires the change of Yin-Yang and Five Elements. So the writer of this paper believes that the Yin-Yang and Five Elements theory must have been in the mind of the Guqin maker when he chose ten strings, which can be divided into five sets, each consisting of two strings, symbolizing one of the Five Elements, and each set of two strings indicates the two sides of objects, namely, Yin and Yang.

From the perspective of ruling class, the philosophers of Zhou dynasty believed that music could consolidate the governance. Instruments like Guqin, were used to guide people's spirit to ethics, morality and sentiment. If the ruler was influenced by music, he would have a peaceful mind and be led to goodness (Zhang, Trans., 2000). With inner peace, the government would be mild. Then the society would be harmonious and so it was with everything. It was also believed that music could bring about changes in morals and moves by cultivating people and leading them to the righteous. The individual who had a good mastery of music had the capacity of assisting the wiser ruler. In an atmosphere of music, people tended to behave politely, which would help to create harmonious collective social life (Li, 2012a). All these indicate that Guqin, as an important musical instrument at that time, carried with it the features of Yin-Yang and Five Elements, mostly expressed in the ten strings.

\section{Conclusion}

Small as the ten-stringed Guqin is, it brings us a broad view on the ruling ideas of its time, attitudes towards ancestors, divinities and heaven, the universe philosophy of Yin-Yang and Five Elements, the specific strategies adopted to cultivating people, the moral pursuit of the intellectuals and upper class and their delicate aesthetic standard. The ideas embodied in the Guqin are generalized from certain deep-rooted traditions in Chinese culture and are inclined to be idealized and conceptualized (Li, 2012b). The ten-stringed Guqin has become a typical cultural reference and standard of implicit meaning for the later Qin manufacture and performance.

For the limitations of historical records, the investigation of the ten-stringed Guqin remains to be constrained. There are still many inquiries to be answered, such as the function of the lines in the Qin body. Some argue that the lines are merely decorations, but others suppose they divide the playing area into sections, which is more convenient for the players. Other questions, like the difference of Yueshan between this ten-stringed Guqin and other Qin, the half-box structure and etc. remain to be explored. 
In this article, the literatures have been summarized and analyzed with the analytical method of the cultural elements, and the culture connotations and functions of the shape and design thought of the ten-stringed Guqin have been textual researched and summed up. The conclusion is put forward for Chinese guqin culture references and cultural symbol provides a new research idea, and the design in the future for Chinese guqin heritage cultural ideas and development provides a new reference way culture connotation.

\section{Subject}

This thesis is the subject conducted by the Ministry of Education Humanities and Social Sciences Research Project (17YJA760072).

\section{Conflicts of Interest}

The author declares no conflicts of interest regarding the publication of this paper.

\section{References}

Cai, Y. (Han Dynasty). Collection of Yuefu Poetry. Zhonghua Book Company.

Chen, G. (1983). Zhuang Zi Annotation (Trans., p. 702). Zhonghua Book Company.

Chen, G. Z., Trans. (2012). Huainanzi (p. 237). Zhonghua Book Company.

Chen, Q., Trans. (2002). Spring and Autumn of the Lu Clan (p. 1536). Shanghai: Shanghai Ancient Books Publishing House.

Han, G., Trans. (1997). Poems and Essays of Seven Sages of the Bamboo Grove Translates Pouring Complete Works (p. 432). Jilin Cultural and Historical Press.

He, X. (2007). Loong and Phonix (p. 115). Current Affairs Press.

Hubei Museum Compiled (2001). Sui County Tomb of Marquis Yi of Zeng. Cultural Relics Press.

Lao, Z. (Spring and Autumn Period). Tao Te Ching.

Li, Y. (2012a). An Analysis of Guqin's Designing Ideas (p. 186). Hundred Schools in Art. 2.

Li, Y. (2012b). An Analysis of Guqin's Designing Ideas (p. 188). Hundred Schools in Art. 2.

Lv, Y. R. (2004). Translation and Annotation of Rites of Zhou (p. 301). Zhongzhouguji Press.

Mu, P., Trans. (2009). Book of Documents (p. 48). Zhonghua Book Company.

Tan, H. (Han Dynasty). New Theory (p. 63). Shanghai: Shanghai Publishing House.

Tan, W. S. (2001a). Important Achievements in the Study of Musical Instruments in Pre-Qin Dynasty (p. 98). Cultural Relics Press.

Tan, W. S. (2001b). Important Achievements in the Study of Musical Instruments in Pre-Qin Dynast (p. 99). Cultural Relics Press.

Wang, D. (2008). The Cultural Origin of Chinese Loogn and Phoenix (p. 215). China Modern Economic Publishing House.

Xu, K., Trans. (1995). Huainanzi (p. 159). Guizhou People Press.

Xu, S. (Han Dynasty, a). Analytical Dictionary of Characters. Zhonghua Book Company. 
Xu, S. (Han Dynasty, b). Analytical Dictionary of Characters (p. 1112). Zhonghua Book Company.

Xu, S. (Han Dynasty, c). Analytical Dictionary of Characters (p. 102). Zhonghua Book Company.

Yan, S. G., Trans. (1990). Journal of Chinese Historical Geography (p. 1327). Zhonghua Book Company.

Yang, B. J. (1981). Commentary on the Spring and Autumn Annals (p. 1222). Zhonghua Book Company.

Yuan, K., Trans. (1992). The Classic of Mountains and Rivers Complete Translation (pp. 271-272). Guizhou People Press.

Zhang, D., Trans. (2000). Historical Records New Note (p. 719). Huawen Press.

Zhang, G. Z. (1986). Special Six Topical in Archaeology. The Important of Ancient Chinese History in World History (p. 4). Cultural Relics Press.

Zhang, J. (1992a). On the Cultural Annotation of Tomb Guardian Beast. Southeast Culture, 4, 68 .

Zhang, J. (1992b). On the Cultural Annotation of Tomb Guardian Beast. Southeast Culture, 4,70 .

Zhang, T. (2014). Evolution of the Playing Skills of Guqin (pp. 139-185). Hundred Schools in Art. 4.

Zhang, Z. M. (1987a). History of Chu Culture (p. 120). Shanghai Publishing House.

Zhang, Z. M. (1987b). History of Chu Culture (p. 121). Shanghai Publishing House.

Zhao, S. G. (1992). Research of Chimes of Marquis Yi of Zeng. Chimes of Marquis Yi of Ze $n$ and Chu Bells (p. 82). Hubei People's Publishing House.

Zhong, C. H. (2013a). The View of the Ancient Qin Dynasty. Journal of the Forbidden City, 10, 37.

Zhong, C. H. (2013b). The View of the Ancient Qin Dynasty. Journal of the Forbidden City, 10, 38 .

Zhu, C. (Northern Song Dynasty). History of Qin (p. 118). Zhonghua Book Company. 